\title{
Grain boundary diffusion and motion associated with precipitation and dissolution in metallic systems
}

\author{
G. SOLÓRZANO ${ }^{(1)}$ \\ Depto. de Ciência dos Materiais e Metalurgia, Pontifícia Universidade Católica do Rio de Janeiro, \\ 22452 Rio de Janeiro, Brazil
}

\begin{abstract}
The microstructural evolution resulting from the combination of grain boundary diffusioncontrolled phase transformations in typical alloy systems is described. For this purpose discontinuous precipitation lamellar products in $\mathrm{Cu}-\mathrm{In}$ and $\mathrm{Ni}$-Sn binary alloys have been subjected to dissolution treatments. Examination of the resulting microstructures have shown that, depending on the alloy composition and annealing temperature, the dissolution could be discontinuous or continuous. In the former, the dissolution process is controlled by diffusion along migrating grain boundaries. In the latter, it is dominated by volume diffusion while the grain boundaries remain stationary. The most striking feature of the post-dissolution microstructure in these alloys is related with two phenomena observed within the previously transformed product: generation of dislocation arrangements or new dislocation-free grains, giving rise to a localized grain refinement. In the absence of any plastic deformation applied to the material, the role played by the internal stresses and the lamellar interfaces generated during the precipitation process is discussed, particularly as the energetic potential for the observed recovery and recrystallization phenomena.
\end{abstract}

\section{INTRODUCTION}

It is widely recognized the role of grain boundaries in controlling the properties of polycrystalline materials. Owing to its practical importance in structural engineering, one of the most important concerns is the thermo-mechanical treatment carried out to obtain recrystallized material with a small grain size. Hence, a basic characteristic of conventional recrystallization practice is the nature of its driving force, i.e., the stored energy originating from an applied plastic deformation. In this context grain growth is a phenomenon to be avoided. On the other hand, in many alloy systems grain boundary migration takes place as a result of diffusional phase transformations, namely discontinuous precipitation (DP) and discontinuous dissolution (DD).

The phenomena of DP is fairly common in binary, ternary and even multicomponent systems [1-3] whose study is attracting interest [4]. This transformation results from the decomposition of a supersaturated solid solution $\alpha^{\circ}$ into a depleted matrix $\alpha^{\prime}$ and a new precipitate phase $\beta$, both growing in a cooperative fashion forming colonies of a very fine lamellae. The reaction fronts are migrating grain boundaries that act as fast diffusion paths, allowing the required composition change at temperatures too low for appreciable volume diffusion.

Discontinuous dissolution (DD) is the reverse of DP in that the reaction front migrates backwards into the two phase structure leaving behind a solid solution $\alpha$. This kind of reaction is limited to only a few alloy

(1)

Current address: Dept. of Materials Science and Engineering, Massachusetts Institute of Technology, MIT Rm 13-5001, Cambridge MA 02139, U.S.A. 
systems, preferably at low concentrations and then only close to the alloy solvus temperature. On the other hand, the continuous dissolution $(\mathrm{CD})$ of the precipitate product is a mechanism controlled by volume diffusion, which restores the single phase material, and is characterized by the imobility of the grain boundaries [5,6]. Its occurrence is favored at temperatures well above the alloy solvus.

The present paper describes the microstructural evolution resulting from the combination of (i) DP followed by DD and (ii) DP followed by $C D$. The first case of retrogression leads to an inhomogenous solid solution restoring the original grain structure. In the second case there is a formation of new grains, with the recrystallized material volume fraction restricted to the previously discontinuous precipitate colonies, thereby suggesting the designation of "discontinuous recrystallization". The former mechanism of dissolution raises fundamental questions associated with the diffusion-induced grain boundary migration phenomenon. The latter is very attractive from the practical point of view, as a method of grain refinement that does not require plastic deformation [7]. In view of space limitation the microstructural results reported here are based primarily on the $\mathrm{Cu}$-In alloy.

\section{EXPERIMENTAL PROCEDURE}

The alloys used for this study were prepared at the Max Planck Institute für Metallforschung, Stuttgart, Germany, from high purity components by induction melting under purified argon and chill cast into rods $10 \mathrm{~mm}$ in diameter. The ingots of $\mathrm{Cu}-7.5 \mathrm{In}$ were sealed in argon and homogenized at $644^{\circ} \mathrm{C}$ for 455 hours. Slabs about $1 \mathrm{~mm}$ thick were checked for segregation in the electron microprobe analyzer. Some slabs, grain size about 400-500 $\mu \mathrm{m}$, were used for metallographic studies and others, intended for transmission electron microscopy (TEM) studies, were cold rolled to $0.1 \mathrm{~mm}$. Both kind of samples, slabs and rolled strips, received the heat treatment schedule, solution treatment, precipitation and dissolution. Information on the treatment conditions were obtained from the existent literature on the discontinuous reaction and from the equilibrium phase diagram of the $\mathrm{Cu}$-In system [8-12]. Several annealing times and temperatures were applied as indicated in Table 1. All treatments were interrupted by quenching in water. The solution treatment applied to the rolled strips generated a fully recrystallized microstructure with grain size of about $150 \mu \mathrm{m}$. Metallographic sample preparation followed conventional mechanical and electrolytic procedures. After electrolytic thinning in $30 \%$ nitric acidmethanol solution at $-30^{\circ} \mathrm{C}$, the samples were observed in a Jeol $200 \mathrm{CX}$ TEM. For the Ni-8 Sn alloy the same procedure was followed varying the homogenization, precipitation and dissolution temperatures as indicated in Table 1. The metallographic sample preparation also followed standard procedures. TEM thin foils were obtained by jet polishing with a $10 \%$ perchloric acid-methanol solution at room temperature.

Table 1. Heat treatment conditions for $\mathrm{Cu}-7.5 \mathrm{In}$ and $\mathrm{Ni}-8 \mathrm{Sn}$

Treatment Temperature Time

\begin{tabular}{l|ll|ll}
\hline \multirow{3}{*}{$\begin{array}{l}\text { Homogenization } \\
\text { Precipitation }\end{array}$} & $\mathrm{Cu}-7.5 \mathrm{In}$ & $\mathrm{Ni}-8 \mathrm{Sn}$ & $\mathrm{Cu}-7.5 \mathrm{In}$ & $\mathrm{Ni-8 \textrm {Sn }}$ \\
\cline { 2 - 5 } & $640,700{ }^{\circ} \mathrm{C}$ & $940{ }^{\circ} \mathrm{C}$ & $2 \mathrm{~h}$ & $2 \mathrm{~h}$ \\
Dissolution & $350,400,420^{\circ} \mathrm{C}$ & $500,600,700^{\circ} \mathrm{C}$ & $5,10,15 \mathrm{~h}$ & $4,6.24 \mathrm{~h}$ \\
\hline
\end{tabular}

\section{RESULTS AND DISCUSSION}

\section{As-aged microstructure}

The reaction front of an as-aged and quenched transformed product in both alloy systems is shown in fig 1. The scale of the lamellar structure as well as the morphology of the bowing grain boundary, growing against capillary forces, can be appreciated; a concave-forward curvature is imposed by the chemical driving force [13]. TEM diffraction contrast is able to reveal interesting features in the singlegrain lamellar colony, such as local disorientation between neighbor $\alpha$ lamellae in the $\mathrm{Cu}-7.5 \mathrm{In}$ alloy (fig. 1a). This observation indicates that non-rigid orientation relationship in the $\alpha^{\prime} / \beta$ interfaces is maintained during precipitate growth and, as a result, internal stresses are incorporated in the material. 

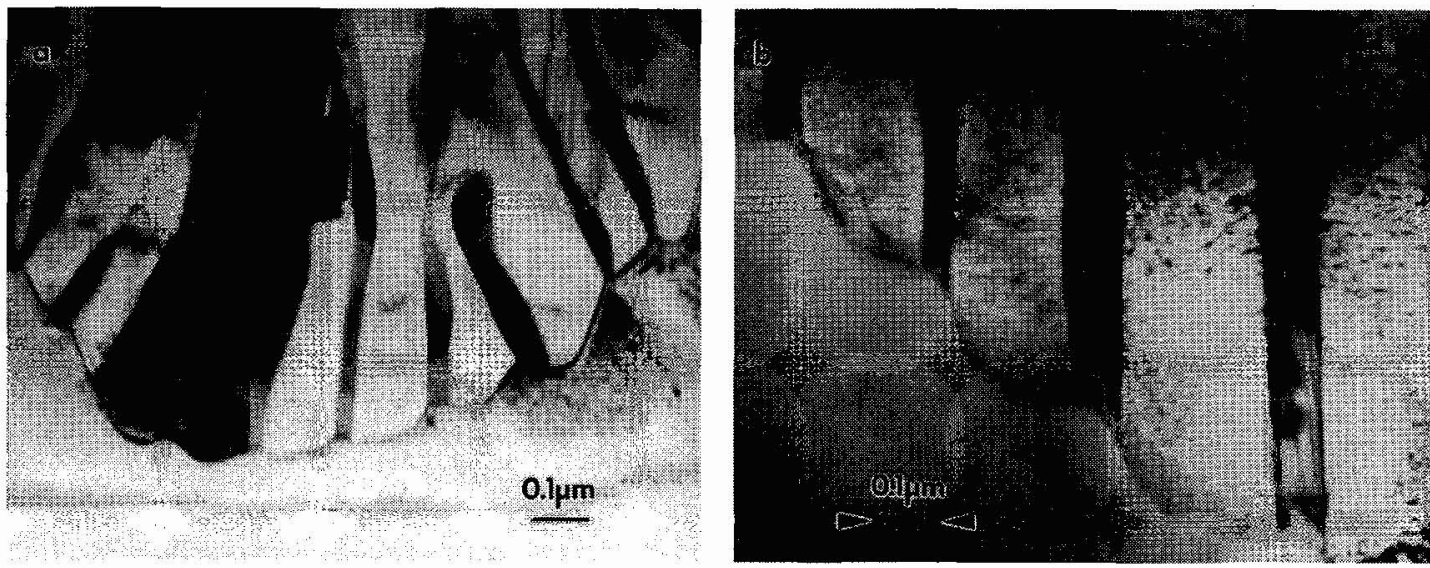

Fig. 1 Discontinuous precipitation reaction fronts of as-aged microstructures. (a) $\mathrm{Cu}-7.5 \mathrm{In}$ after anneal at $350{ }^{\circ} \mathrm{C}$ for $15 \mathrm{~h}$. (b) Ni-8 Sn after anneal at $600{ }^{\circ} \mathrm{C}$ for $6 \mathrm{~h}$. Bright field TEM micrographs.
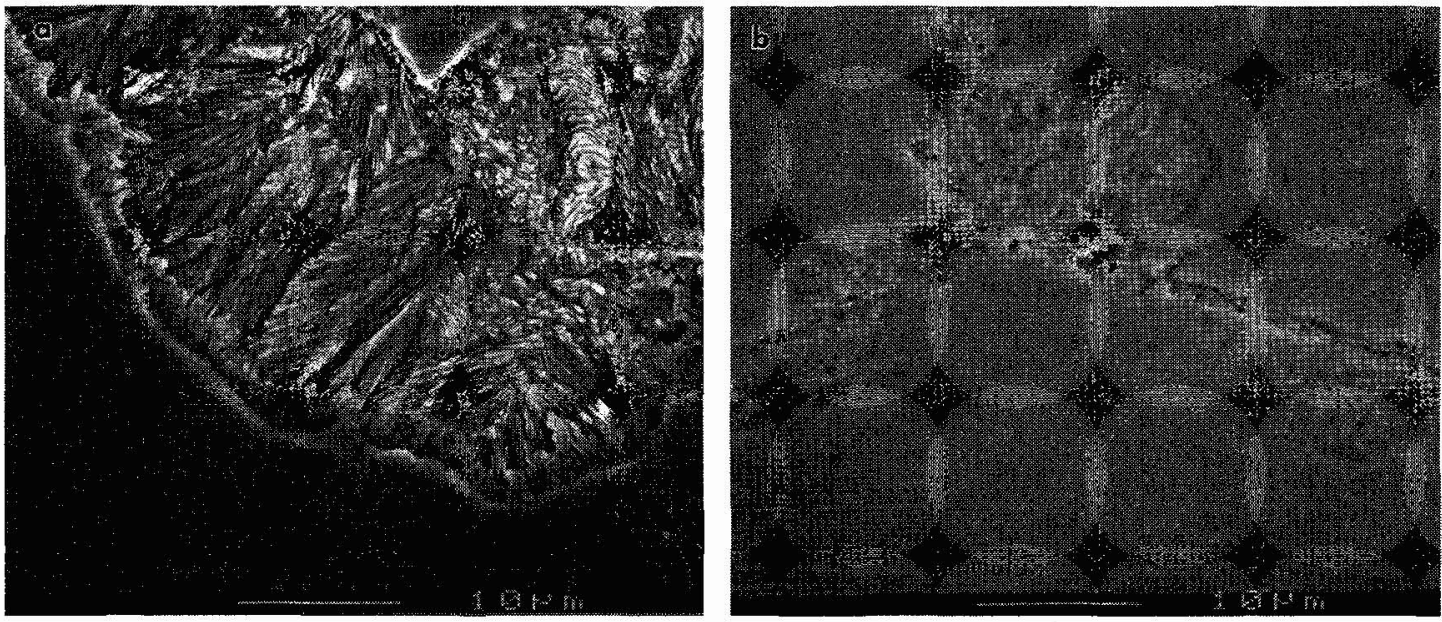

Fig. 2 Microstructural evolution of a DP product of $\mathrm{Cu}-7.5 \mathrm{In}$ at $350^{\circ} \mathrm{C} / 15 \mathrm{~h}$ undergoing discontinuous dissolution. (a) after solution anneal at $4800^{\circ} \mathrm{C}$ for $10 \mathrm{~s}$. (b) after solution anneal at $480^{\circ} \mathrm{C}$ for 120 s. SEM micrographs.

\section{Discontinuous dissolution (DD)}

The SEM micrographs of fig. 2 represent a typical sequential view of a DP product undergoing DD. For an aging treatment of $15 \mathrm{~h}$ at $350^{\circ} \mathrm{C}$ most of the grain boundaries have moved generating colonies of finely spaced precipitate lamellae. After only $10 \mathrm{~s}$ of anneal at $480^{\circ} \mathrm{C}$, which is slightly above the alloy solvus temperature, the grain boundaries have moved backwards a distance of about $3 \mu \mathrm{m}$ thereby partially dissolving the precipitate structure (fig. 2a). An annealing time of $120 \mathrm{~s}$ is enough for most of the grain boundaries to return to their original position leaving behind a ghost image of the former DP colonies (fig. 2b). It is clear that at this temperature interface diffusion globally dominates over volume diffusion. As a consequence, and driven by a chemical driving force the grain boundaries move, consuming the precipitates, at an average speed of $400 \mathrm{~nm} / \mathrm{s}$ (about 1000 times faster than during the precipitate growth process). The TEM micrographs of fig. 3 show in more detail the characteristics of 

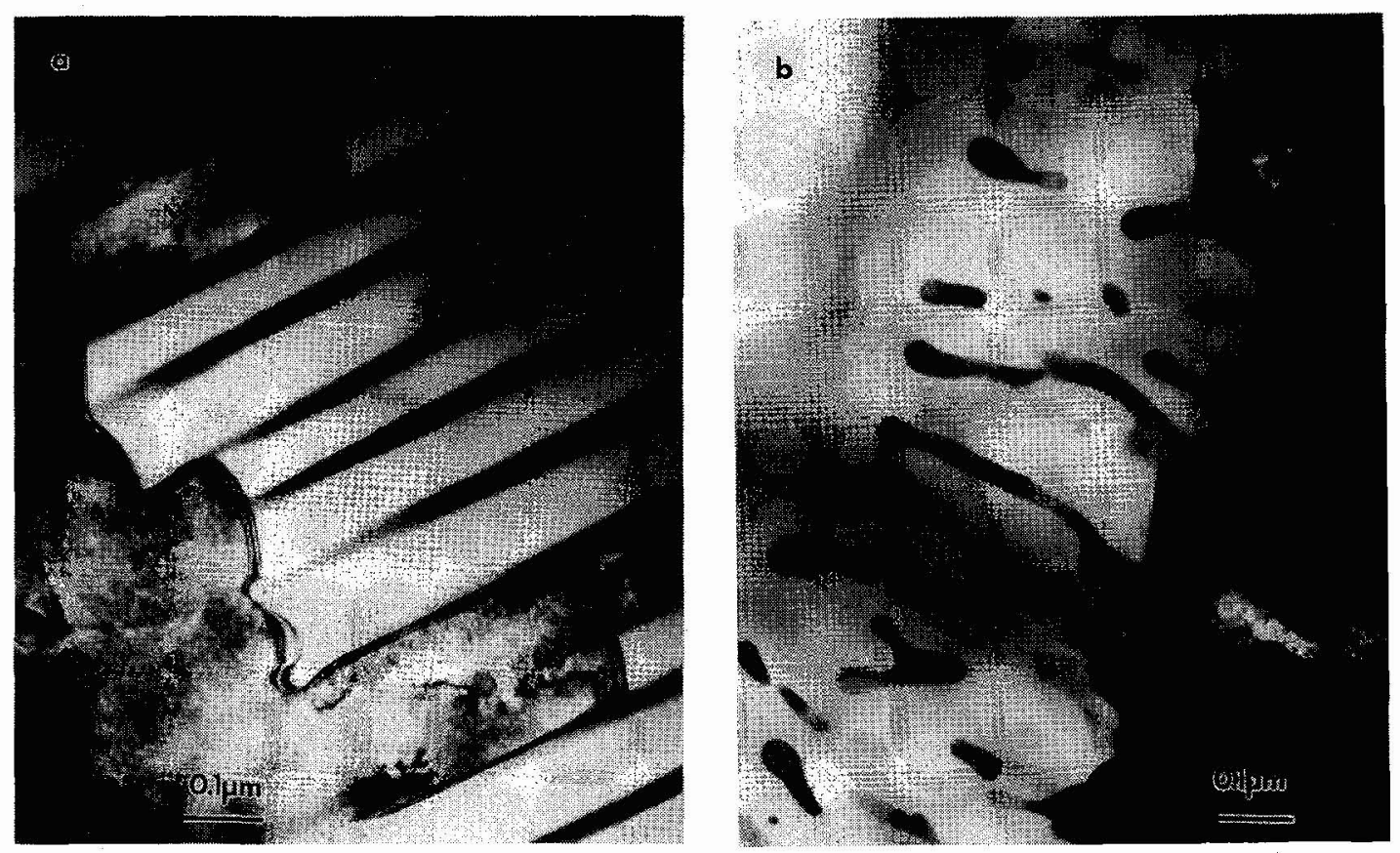

Fig. 3 Discontinuous dissolution reaction fronts in $\mathrm{Cu}-7.5 \mathrm{In}$ aged at $350{ }^{\circ} \mathrm{C}$ for $15 \mathrm{~h}$ followed by quenching and dissolution anneal at $380^{\circ} \mathrm{C}$ for $10 \mathrm{~s}$. (a) illustrates the resulting stronger steplike grain boundary. (b) reveals that the grain boundary migration does not necessarily lead to a complete precipitate dissolution. TEM micrographs.
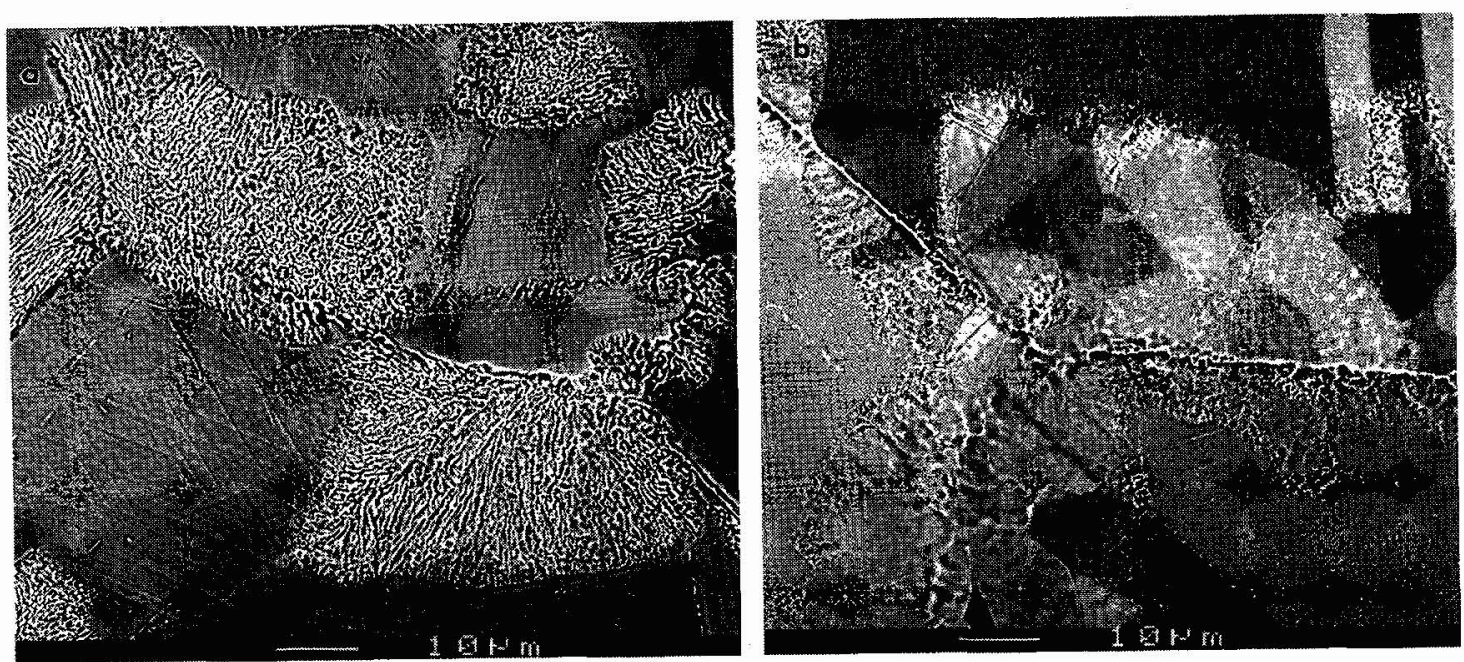

Fig. 4 Discontinuous recrystallization accompanying continuous dissolution of $\mathrm{Cu}-7.5 \mathrm{In}$ previously aged at $350^{\circ} \mathrm{C}$ for $15 \mathrm{~h}$. (a) after solution anneal at $580^{\circ} \mathrm{C}$ for $5 \mathrm{~s}$. (b) after solution anneal at $558^{\circ} \mathrm{C}$ for $60 \mathrm{~s}$. SEM micrographs. 

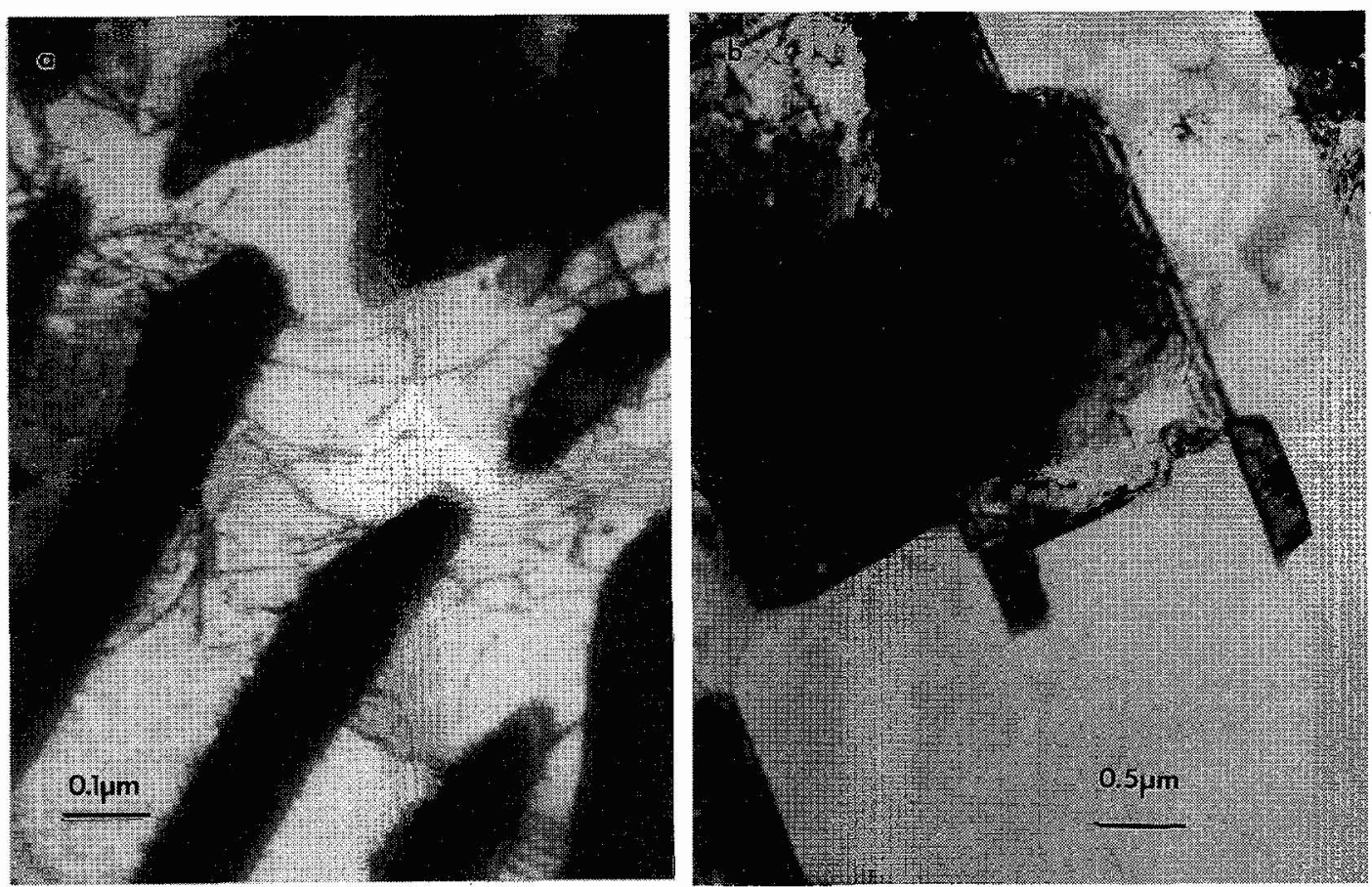

Fig. 5 Bright field TEM micrographs of: (a) DP product of aging at $400{ }^{\circ} \mathrm{C}$ for $10 \mathrm{~h}$ showing $\alpha^{\prime} / \beta$ misfit dislocations and matrix dislocations; (b) after solution anneal at $580{ }^{\circ} \mathrm{C}$ for $10 \mathrm{~s}$ showing a sub-grain structure.

the DD reaction front, namely the resulting boundary rugosity (fig. 3a) and the incompleteness of the dissolution (fig. 3b). For the purpose of the present paper, the kinetics of DD will not be discussed here; there are rather few well documented cases of DD in other alloy systems [3]. An important aspect to keep in mind is the instability and mobility of grain boundaries associated with interface diffusion.

\section{Continuous dissolution (CD)}

The microstructural evolution of a DP product undergoing CD is shown in fig. 4. As for the previous example the aging conditions were maintained at $350^{\circ} \mathrm{C} / 15 \mathrm{~h}$. The dissolution treatments were carried out at $580{ }^{\circ} \mathrm{C}$, i. e., about $100^{\circ} \mathrm{C}$ above the solvus. At this temperature volume diffusion mechanisms dominate throughout the entire DP microstructure. After only $5 \mathrm{~s}$ of anneal at $580^{\circ} \mathrm{C}$ the grain boundaries reaction fronts have remained stationary but the lamellar structures are no longer straight (fig. 4a). After $30 \mathrm{~s}$ of dissolution the lamellar structures have given rise to new grains inside the former DP colonies (fig. 4b). To elucidate the source of the discontinuous recrystallization (DR) phenomenon, it is necessary to establish the nature of its driving force. In a previous publication [7] it was proposed, supported by TEM observations in the same alloy, that the lamellar interfaces of DP product have the capacity of storing enough energy which will be transformed into driving force to allow, upon annealing, the nucleation and growth of new grains to occur. Current TEM studies indicate that the $\alpha^{\prime} / \beta$ interfaces are semicoherent and also that an extra component of elastic strain is incorporated in the DP product. Figure 5a shows a lamellar product with interface and punched out dislocations, typical of high misfit interface boundaries. In figure $5 \mathrm{~b}$ the same product is shown after $10 \mathrm{~s}$ of anneal at $580^{\circ} \mathrm{C}$. It can be seen that the dislocations reorganize into subgrains which will lead to new grain formation. The mechanisms of DR will be the subject of a separate publication. 


\section{CONCLUSIONS}

It has been demonstrated that adequate heat treatment carried out in $\mathrm{Cu}-7.5 \mathrm{In}$ allows for the development of two extreme dissolutions mechanisms of DP products:

1. Discontinuous dissolution, controlled by interface diffusion, in which the grain boundaries migrate to their original position leaving behind an inhomogenous solid solution.

2. Continuous dissolution, controlled by volume diffusion, in which the grain boundaries remain stationary giving rise to a phenomenon of discontinuous recrystallization (DR). It is suggested that the driving force for DR is related to the stored energy in the DP product as elastic strain and by the semicoherent lamellar interfaces.

Similar results, not reported here, have been observed in the Ni-8 Sn alloy.

\section{ACKNOWLEDGEMENTS}

Thanks are due to Prof. W. Gust, MPI, Stuttgart, for providing the alloy used in this study. The TEM studies were carried out at the Laboratoire LTPCM-INPG, Grenoble. The author is indebted to the CEE, Brussels, for a fellowship award.

\section{REFERENCES}

[1] GUST w., in Phase Transformations, Ser 3, 11-1, Spring Res. Conf., Univ. of New York (1979) II-27.

[2] WILLIAM D.B., BUTLER, E.P., Int. Met. Reviews 3 (1981) 158.

[3] GUST W., Habilitationsschrift zur Erlangung der Leherberechtigung, Univ. Stuttgart (1980).

[4] PURDY G.R., in Phase Transformations 87, Cambridge (1987).

[5] SOLORZANO I.G., WHEATHERLY G.C., Mat. Sci. and Eng. 81 (1986) 101.

[6] GUST W., CHUANG T.H., FOURNELLE R.A., $7^{\circ}$ CBECIMAT, Rio de Janeiro, (1986) 7.

[7] SOLORZANO I.G., COHN J.A., ANDRADE R.M.N., Mat. Sci. and Tech. 7 (1991) 565.

[8] SHAPIRO J.M, KIRKALDY J.S., Acta Met. 16 (1968) 1239.

[9] FOURNELLE R.A., CLARK J.B., Met. Trans. 3 (1972) 2757.

[10] GUST W., HINTZ M.B., ROLL U., Acta Met. 28 (1980) 1235.

[11] GUPTA S.P., Mat. Sci. and Eng. 21 (1975) 211.

[12] KIM W., MEYRICK G., SHEWMON P.G., Scripta Met. 17 (1983) 1435.

[13] SOlORZANO I.G., PURDY G.R., WHEATHERLY G.C., Acta Met. 32 ( 1984) 1709. 